\title{
Shaking Table Test of the Full-scaled Semi-rigid Composite Beam Frame
}

\author{
Mingji FANG \\ College of Civil Engineering \\ Shanghai Normal University \\ Shanghai, China \\ e-mail: fangmji@126.com
}

\author{
Ting LU \\ College of Civil Engineering \\ Shanghai Normal University \\ Shanghai, China \\ e-mail: 710659694@qq.com
}

\author{
Dazhu HU \\ College of Urban Construction and Safety Engineering \\ Shanghai Institute of Technology \\ Shanghai, China \\ e-mail: dazhuhu@163.com
}

\author{
Yifan PAN \\ College of Civil Engineering \\ Shanghai Normal University \\ Shanghai, China \\ e-mail:1558758233@qq.com
}

\author{
Wensheng XU \\ College of Civil Engineering \\ Shanghai Normal University \\ Shanghai, China \\ e-mail: 3293458933@qq.com
}

\begin{abstract}
A shaking table test of a full-scaled semi-rigid composite beam frame has been carried out to study the dynamic characteristics and the failure mode, the aim of the research is to provide a theory basis for the design of the composite frames. The analysis was concentrated on the dynamic characteristics, displacement response, acceleration response, internal force response of joints, and the failure mode of the structure was also involved, the outcome of the test indicates the semi-rigid frame perform well in earthquake. When subjected to an extreme earthquake loading with the peak acceleration 1.2 gal, the whole structure had no visible damage and only showed larger plastic deformation in semirigid composite joints and the heels, of which means the frame can be used in high seismic fortification intensity regions.
\end{abstract}

Keywords-composite beam frame; semi-rigid connection; shaking table test; finite element analysis; elastic-plastic timehistory analysis; seismic behavior

\section{INTRODUCTION}

In recent two decades, scholars nationally and abroad have carried out theoretical researches on semi-rigid connections accompanied by massive experimental investigations [1-3]. Afterwards, the mechanical and hysteretic behavior of the composite joints with or without combined action of concrete floor is conducted. Elnashai [4] carried out the cyclic loading and pseudodynamic testing analysis. Marwan N. Nader [5-6] studied the seismic behavior of the semi-rigid steel frames. Otherwise, most of the research was focused on static loading.

The low stiffness of semi-rigidly connected composite frames will cause large displacement, which therefore maybe cannot satisfy the demands of earthquake protection Therefore, this study conducts a shaking table test on a full scale composite [7-8] frame in order to further explore its seismic behavior and the failure mode under the frequently and rare earthquakes.

\section{EXPERIMENTAL MODEL}

In order to better reflect the real seismic performance of semi-rigid composite frames and the semi-rigid joints, a fullscale test model was designed. Considering the parameters of the vibrating table (table size, lifting height, and maximum table load), the plane size of test model was $3.1 \mathrm{~m} \times 4 \mathrm{~m}$ and the height of story was $2.8 \mathrm{~m}$. The structure was 2-story high with 1 span as shown in Fig. 1.

In this frame structure, the columns were designed as hotrolled H-shaped beam with the cross-section $\mathrm{H} 150 \times 150 \times 8 \times 8$ and the beams used hot-rolled $\mathrm{H}$-shaped beam with the section of $H 180 \times 100 \times 6 \times 8$, the thickness of end plate was $6 \mathrm{~mm}$ and the10.9 level M16 type high strength bolts were used in the connections. The flange width of the composite beam was $1200 \mathrm{~mm}$ and the concrete composite deck slabs were used in the model with the slab ribs perpendicular to the main girders. Flush end-plate connections were used in the semi-rigid connections. Due to the limitation of the lifting capacity for laboratory crane, the concrete's continuous pouring was not used on whole model floor-slab, but only within the effective floor width scope. The depth of the concrete composite deck slab was $140 \mathrm{~mm}$ with the $75 \mathrm{~mm}$ steel wave height and $65 \mathrm{~mm}$ concrete depth. Furthermore, the strength of the concrete was C20.

In order to meet the requirement of the shear connection, there was a row shear studs set in every intersect areas of the 
slab wave troughs and the steel girders. The diameter of studs was $19 \mathrm{~mm}$ and the height after welding was $110 \mathrm{~mm}$. The concrete floor-slab adopted two-layer reinforcement and the thickness of protective layer was $20 \mathrm{~mm}$. The upper layer longitudinal reinforcement was $10 @ 120$ and the reinforcement ratio was $1 \%$ (Reinforcement ratio is defined as the ratio of total area of the reinforcement in the floor-slab and the area of concrete floor which above the ribbed steel sheet). The transversely distributed reinforcement was $10 @ 120$. Furthermore, a reinforcement of diameter 10 was installed in each wave trough.

After the installation, the model was hoisted and fixed to the vibration table. Then, the added mass, displacement transducers, accelerometers and strain gauges were set in the designed positions.

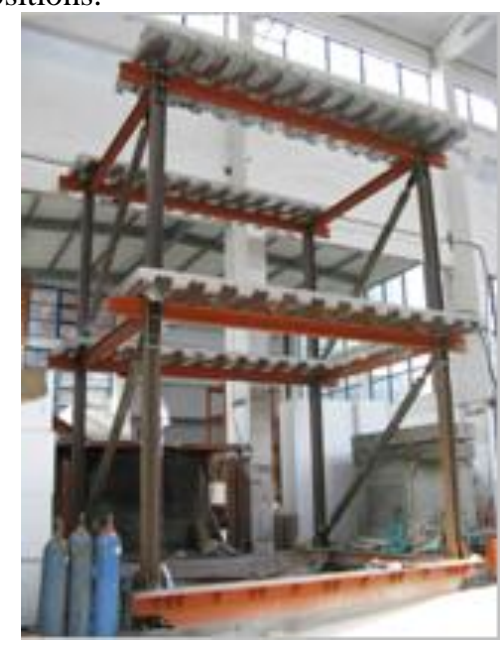

Figure 1. Test frame

\section{TEST SCHEME}

The main purpose of the test was to research the dynamic characteristics of the specimen; including the floor acceleration response; the displacement of each floor; the

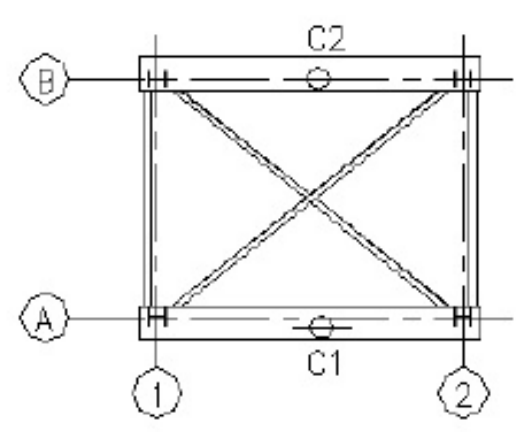

(a) Layout of base

(a) Layout of base

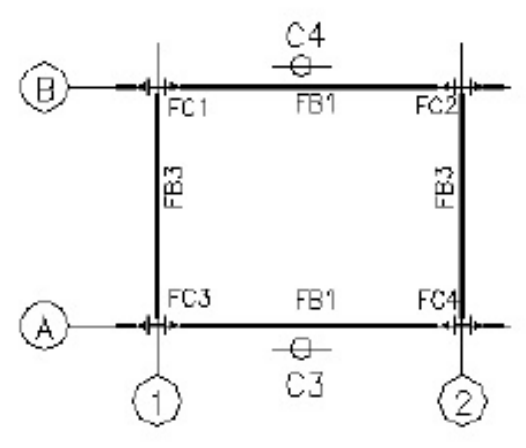

(b) Layout of second floor

Figure 2. Accelerometer arrangement change of semi-rigid connection bending moment; the dynamic strain response of column footing. According to the testing contents we concerned, six accelerometers, 16 strain gauges and 5 Linear Variable Displacement Transducers (LVDTs) were employed in the model and the layout schemes are illustrated in Fig. 2 and Fig. 3 respectively.

\section{TEST LOADING PROCEDURE}

The input wave of the shaking table was generated by the 1940-EL-Centro (EL). In order to show the representative experimental results, the seismic waves were compressed on the time axis and the time similarity ration was set as 1:2. The unidirectional loading method was applied in this test. Before each loading step, the white noise frequency test was used to measure the dynamic behavior of the full-scale model.

\section{FAILURE MODES AND SEISMIC BEHAVIOR}

The cracks in the floor after the vibration are shown in Fig. 4 and the following regulations can be seen from the cracks:

(a) There were more cracks in the middle layer than that of the top layer, which means that a more severe damage happens in the middle layer rather than the top.

(b) Each and every node shares at least one transverse cracks which extended throughout the entire floor, and the cracks will be through the medial flange, where the floor was intersected by the frame column and the position was where the semi-rigid connection was located, which means the force in this position reached the maximum value.

(c) The crack first appeared in the column flange, which can be judged from the crack width. While the follow-up lateral cracks located in the composite beam began to appear from the edge of the floor.

(d) The cracks near the columns were penetrated through the whole floor thickness, meanwhile, the diagonal cracks appeared along the floor.

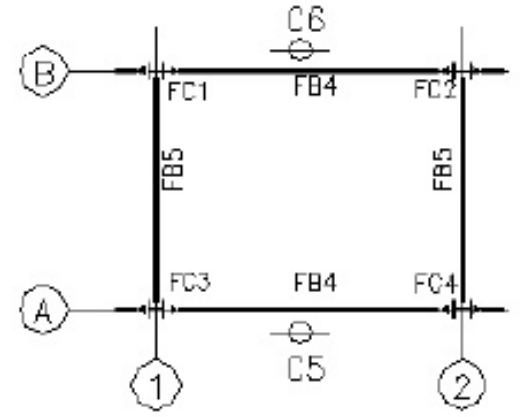

(c) Layout of top floor 


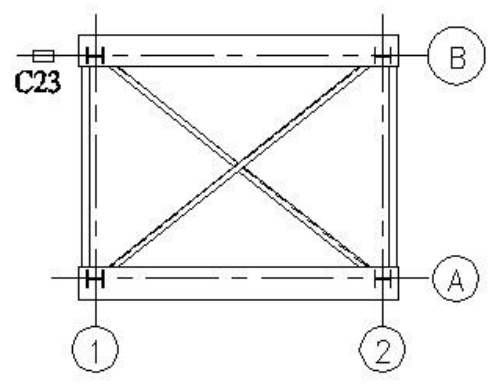

(a) Layout of base

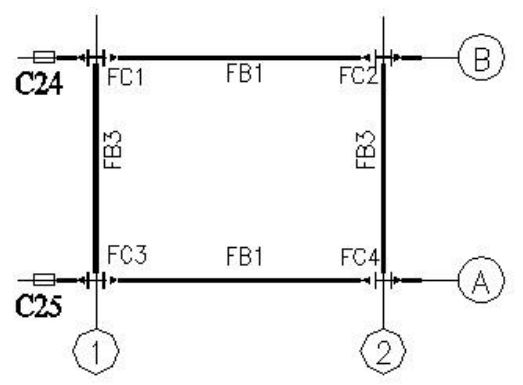

(b) Layout of second floor

Figure 3. LVDTs arrangement

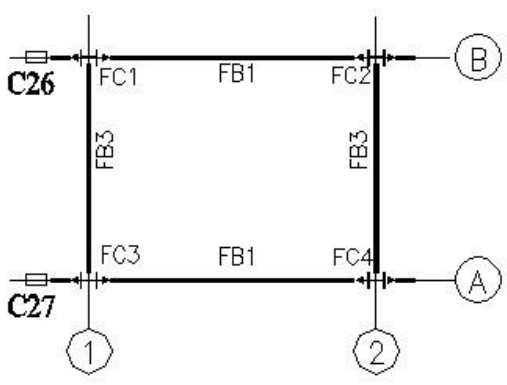

(c) Layout of top floor

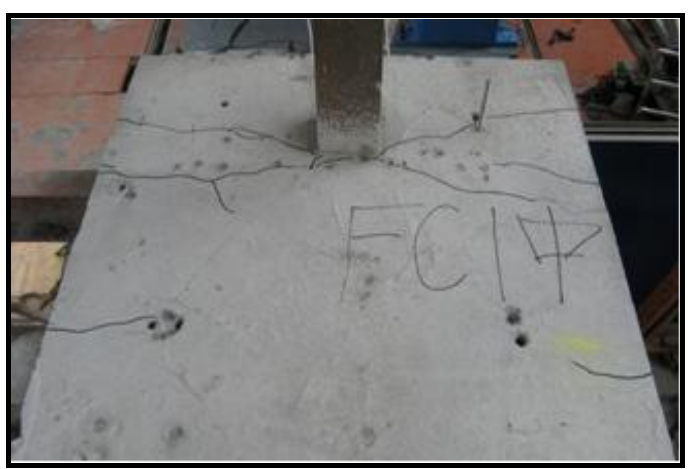

(a) FC1 Cracks on intermediate layer node

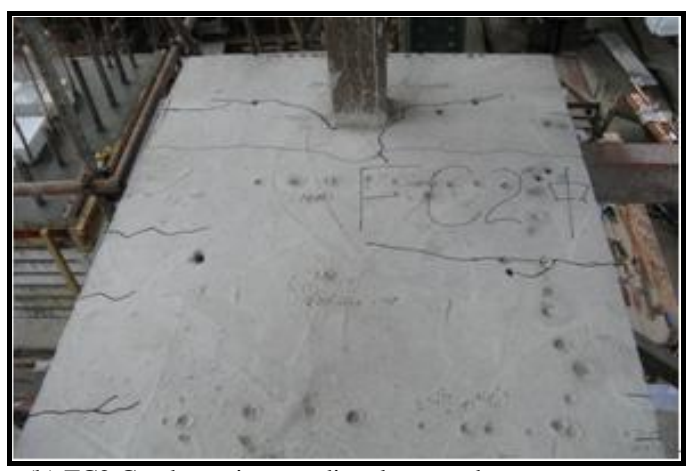

(b) FC2 Cracks on intermediate layer node

Figure 4. Cracks in the slab

\section{A. Dynamic Characteristics}

Before the test and after each unidirectional loading grade, the white noise wave was used to scan the model in order to monitor the change of its dynamic properties (Table 1). As shown in this table, when the seismic load increased, the natural frequency of vibration of the model decreased.

In addition to the natural frequency, damping ration is another important dynamic characteristic and the white noise wave was also used to analysis them (Table 2). As shown in this table, with the seismic load strengthened, the damping ratio of the model increased gradually.

\section{B. Acceleration Response}

In order to study the acceleration response of the model, the floor acceleration peak values were divided by the acceleration peak value of the structure base. Therefore, the acceleration magnification factor for each testing point was given and figure 5 showed the dynamic factor curves for each floor at every seismic intensity load.

The figure shows that the magnification factor of the second floor is greater than others. With the increment of seismic intensity, all the dynamic magnification factors decrease.

TABLE I. SCANNING FREQUENCY OF MOdEL (Hz)

\begin{tabular}{|c|c|c|c|c|c|c|c|c|}
\hline Seismic load & Initial frequency & $\mathbf{0 . 0 5 g}$ & $\mathbf{0 . 1 0 g}$ & $\mathbf{0 . 2 0 g}$ & $\mathbf{0 . 3 0 g}$ & $\mathbf{0 . 5 0 g}$ & $\mathbf{0 . 7 0 g}$ & $\mathbf{1 . 0 g}$ \\
\hline Frequency & 2.441 & 2.441 & 2.441 & 2.441 & 2.343 & 2.246 & 2.148 & 1.855 \\
\hline
\end{tabular}

TABLE II. SCANNING DAMPING Ratio OF Model

\begin{tabular}{|c|c|c|c|c|c|c|c|c|}
\hline Seismic load & Initial damping ratio & $\mathbf{0 . 0 5 g}$ & $\mathbf{0 . 1 0 g}$ & $\mathbf{0 . 2 0 g}$ & $\mathbf{0 . 3 0 g}$ & $\mathbf{0 . 5 0 g}$ & $\mathbf{0 . 7 0 g}$ & $\mathbf{1 . 0 g}$ \\
\hline Damping ratio & 0.022 & 0.022 & 0.0235 & 0.0243 & 0.024 & 0.029 & 0.027 & 0.049 \\
\hline
\end{tabular}




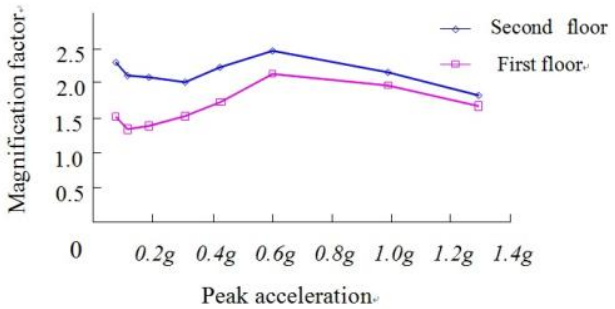

Figure 5. Dynamic enlargement coefficients

\section{Displacement Reaction}

According to the displacement response of floors and shaking table measured by the displacement meters, the story drift ratio can be calculated.

When the seismic intensity reached $0.2 \mathrm{~g}$ and $0.30 \mathrm{~g}$, the story drifts reached $1 / 297$ and $1 / 166$, respectively. The maximum story relative displacement of the first floor can even reach $1 / 40$ at the seismic load $1.2 \mathrm{~g}$, at that time, the column strain reached 0.0036 and the foot of the column has already yielded but without local buckling.

\section{Joint Forces}

The strain gauges of FC1 column frame in second floor kept staying in elastic stage in the whole loading process, hence, the bending moment can be directly obtained by calculation, then, we can get the node bending moment with the equilibrium of node.

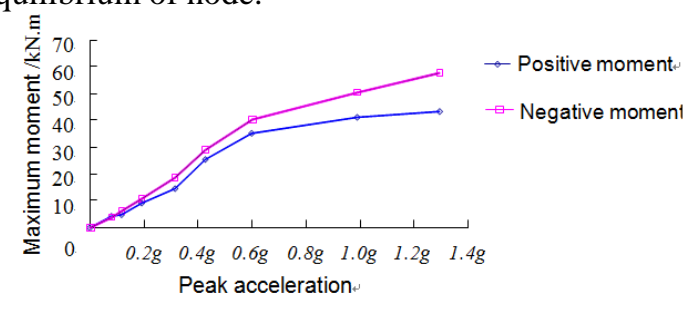

Figure 6. Moment of the semi-rigid connection

Figure 6 shows the maximum positive and negative moment of semi-rigid nodes under different seismic intensity load. With the strengthening of earthquake intensity, connection moment value increased. Before a condition of $0.30 \mathrm{~g}$, it basically showed linear change. But after this condition, the growth rate of moment gradually decreased and showed nonlinear changes. When the seismic intensity reached $1.20 \mathrm{~g}$, the maximum negative moment was $58.0 \mathrm{kN} \cdot \mathrm{m}$ and the maximum positive moment was $43.0 \mathrm{kN} \cdot \mathrm{m}$. Compared with the theoretical analysis, the flexural capacity of the composite node under positive moment was $30.4 \mathrm{kN} \cdot \mathrm{m}$ and that of negative moment was $58 \mathrm{kN} \cdot \mathrm{m}$, which were close with the experimental values.

\section{CONCLUSIONS}

(a) The semi-rigid composite frame keeps in good condition under the seismic fortification intensity $0.30 \mathrm{~g}$, and the maximum story drift without significant damage is $1 / 186$ in the test. Therefore, the allowable deformation can be recommended to choose as 1/200 under frequently occurred earthquake.

(b) The test results show that the damage of bottom connections is more serious than that of top floor. Meanwhile, the column footing will yield under the strong earthquake but without bucking, which means through reasonable design, the failure mode of semi-rigid composite frame is the underlying pedestal and composite connections destruction.

(c) In rare earthquake action $(1.2 \mathrm{~g})$, the maximum story drift can reach up to $1 / 40$. Meanwhile, there is a serious damage to the nodes but no obvious destruction to the main structure, and the joints strength and stiffness decreases greatly at the same time.

\section{REFERENCES}

[1] Sun Fei-fei, Li Guo-qiang, Hu Linhua. "New development in experimental research on beam-to-column composite joints", [J]. Progress in Steel Building Structures, 2004, 6(2): 37-42.

[2] Li Guo-qiang, Shi Wen-long, Xiao Yong. "State of the art of research on semi-rigid compostie beam-to-column joints", [J]. Progress in steel Building Structures, 2007, 9(4):11-22.

[3] Li T Q, Moore D B, Nethercot D A, Choo B S. "The experimental behaviour of a full-scale, semi-rigidly connected composite frame: Overall considerations", [J]. Journal of Constructional Steel Research, 1996, 39(3): 167-191.

[4] Elnashai A S, Elghazouli A Y, Denesh-Ashtiani F A. "Response of semirigid steel frame to cyclic and earthquake loads", [J]. Journal of Structural Engineering, 1998, 124(8): 857-867.

[5] Nader M N, Astaneh-Asl A. Shaking table tests of rigid, "semirigid and flexible steel frames", [J]. Journal of Structural Engineering, 1996, 122(6): 589-596.

[6] Nader M N, Astaneh-Asl A. "Dynamic behavior of flexible, semirigid and rigid steel frames", [J] Journal of Constructional Steel Research, 1991, 20(3): 179-192.

[7] Dhanalakshmi M, Byfield M P, Couchman G H. "Composite connections at perimeter loacations in unpropped composite floors", [A]. Proceeings of the Third International Conference on Advances in Steel Structures, 9-11 December, 2002, Hong Kong, China, 2002: 261-269.

[8] Wang Jin-feng. "The Practical Design Approach of Semi-rigidly Connected Composite Frames under Vertical Loads", [D]. Shanghai: Tongji University, 2005. 